\title{
UDC 621.039.674.3 \\ APPLICATIONS OF FUSION-FISSION HYBRID SYSTEMS FOR NUCLEAR FUEL CYCLE
}

\author{
M.N. Shlenskii ${ }^{1,2}$, B.V. Kuteev ${ }^{2}$ \\ ${ }^{I}$ National Research Nuclear University Moscow Engineering Physics Institute, Plasma Physics Department, Moscow, Russia \\ ${ }^{2}$ NRC «Kurchatov Institute», Tokamak Division, Moscow, Russia
}

This paper comprises results presented at the FUNFI4 conference. The reported research focuses on the prospective utilization of a fusion-fission hybrid system (FFHS) as a powerful neutron source capable of transmuting minor actinides (MAs; Np, Am, Cm) from spent nuclear fuel (SNF). Calculations simulating nuclide kinetics in MA-bearing metal fuel were performed for three 40-MW fusion power FFHS reactors, intended for different purposes (demonstration, pilot-industrial, and industrial). In addition, the research assessed potential requirements for FFHSs and their role in Russia's nuclear power program. A model created by AO «Proryv» was used to analyze the development of the Russian nuclear power system with integrated FFHSs. MA quantities expected to be produced and transmuted in the integration scenario were estimated. The results suggest that just one hybrid facility's capacity would be enough to achieve a $\sim 28 \%$ MA decrease in the Russian power system by 2130 .

Key words: fusion-fission hybrid system (FFHS), fusion neutron source (FNS), minor actinides (MAs), partitioning and transmutation $(\mathrm{P} \& \mathrm{~T})$, closed nuclear fuel cycle.

DOI: $10.21517 / 0202-3822-2021-44-2-139-144$

\section{ПРИМЕНЕНИЕ ГИБРИДНЫХ СИСТЕМ СИНТЕЗА-ДЕЛЕНИЯ В ЯДЕРНОМ ТОПЛИВНОМ ЦИКЛЕ}

\begin{abstract}
М.Н. Шлёнский ${ }^{1,2}$, Б.В. Кутеев ${ }^{2}$
${ }^{1}$ Национальный исследовательский ядерный университет «Московский инженерно-физический институт», Кафедра физики плазмы, Москва, Россия

${ }^{2}$ НИЦ «Курчатовский институт», Отдел токамаков, Москва, Россия

Эта статья содержит представленные на конференции FUNFI4 результаты исследований возможного использования перспективных гибридных систем синтеза-деления (ГССД) в качестве мощного источника нейтронов, способного трансмутировать минорные актиниды (MA) Np, Am, Cm из отработавшего ядерного топлива (ОЯТ). Расчёты, моделирующие кинетику нуклидов в металлическом топливе, содержащем МА, были выполнены для трёх ГССД мощностью 40 МВт, предназначенных для различных целей (демонстрационной, опытно-промышленной и промышленной). В ходе исследования были оценены потенциальные потребности в ГССД и их роль в российской ядерной энергетике. Модель, созданная АО «Прорыв», была использована для анализа развития российской атомной энергетики с интегрированными в неё ГССД. Были оценены количества МА, которые, как ожидается, будут получены и трансмутированы в сценарии, охватывающем все три рассмотренных вида ГССД. Результаты расчётов показывают, что трёх ГССД (по одной установке каждого вида) будет достаточно для снижения количества МА, наработанных российской энергосистемой к 2130 г., на 28\%.
\end{abstract}

Ключевые слова: гибридная система синтеза-деления, термоядерный источник нейтронов, минорные актиниды, разделение и трансмутация нуклидов, замкнутый ядерный топливный цикл.

\section{INTRODUCTION}

One of the most crucial issues for the nuclear engineering community is to develop a closed nuclear fuel cycle that would extend the use of nuclear energy to more than 1000 years and make nuclear technologies more environmentally acceptable, cost-effective and safe. A further aspect of this issue is the management of SNF and radioactive waste (RW).

As reported in $[1,2]$ SNF from a light water reactor (LWR) typically contains more than $95 \%$ of $\mathrm{U}$, about $1 \%$ of $\mathrm{Pu}, 0.1 \%$ of MAs and around 3-4\% of fission products (FPs). Plutonium and MA, although present in low concentrations, are the main contributors to the SNF's long-term radiotoxicity [2]. The radiotoxicity of FPs declines much faster compared to that of actinides. It reaches radioactive equilibrium with respect to uranium ore in about 300 years [2]. If not reprocessed and transmuted, SNF reaches the natural radiotoxicity level only after 100000 years [2].

In this context, SNF reprocessing via separation of minor actinides, $\mathrm{Pu}$ and $\mathrm{U}$, seems to be a promising option for future nuclear energy production and SNF management [3]. Pu and U could be reused in fission reactors. FPs could be utilized as sources of radiation to reduce the amount of radioactive waste. As mentioned above, actinides are much slower than FPs in terms of radioactivity decay. This problem can be solved by transmuting MAs via fission reactions producing FPs. The strategy is known as partitioning \& transmutation (P\&T) [1].

Some of MAs' neutronics features make them less suited for transmuting with subcritical systems than with critical reactors. These include:

- a very hard spectrum required for the fission of most MAs due to the «threshold» character of their fission cross-sections; 
- the capture-to-fission ratio, $\alpha$ (the ratio of the nonfission capture cross section to the fission cross section) for a given neutron spectrum is crucial to ensuring an effective transmutation [4];

- MA nuclides have small fractions of delayed neutrons (e.g., 0.00127 for ${ }^{241} \mathrm{Am}, 0.00214$ for ${ }^{239} \mathrm{Pu}$ and 0.0172 for $\left.{ }^{238} \mathrm{U}\right)$

- the number of prompt neutrons per fission increases with initial neutron energy. Thus, the higher the initial neutron energy, the more effective the neutron utilization.

One of the most promising approaches to solving this problem is to use of a fusion reactor as a source of high energy neutrons. This is investigated, for example, in [1, 5-10].

Although the use of FFHSs for MA transmutation is subject of many research works, most of those works deal with early stages of designing a real-life facility or have no intention of designing a real-life facility at all. Furthermore, many studies lack a comprehensive analysis of the problem or overlook the fact that not only transmutation parameters are essential, but also the comparison with alternative transmutation techniques and the assessment of the impact, which the integration of FFHSs may produce on the nuclear power system.

\section{METHODS, MODELS AND DATA}

All three hybrid reactor types identified by the road map for the NRC «Kurchatov Institute» project are based on a tokamak with a blanket containing fissile materials and lithium. At present, the demo FFHS version (DEMO-FNS) is in the design stage. Two other hybrid reactors envisaged by the road map have a pilotindustrial and industrial designation (PIHR and IHR, respectively).

The DEMO-FNS features a high-end design, which is also more sophisticated and elaborate compared to the other two. PIHR and IHR have a similar build with slightly different parameters. Tokamaks used in the discussed hybrid systems have the following identical parameters: major plasma radius $R_{0}=320 \mathrm{~cm}$, minor plasma radius $a=100 \mathrm{~cm}$, plasma current $I_{\mathrm{p}}=5 \mathrm{MA}$, toroidal magnetic field $B_{\mathrm{t} 0}=5 \mathrm{~T}$, fusion power $P_{\text {fus }}=40 \mathrm{MW}$ (corresponding $t_{\mathrm{o}} \sim 1.4 \cdot 10^{19} \mathrm{n} / \mathrm{s}$ for the D-T-reaction) and effective fuel irradiation time of 5 years. DEMO-FNS, PIHR and IHR are due to be started up in 2033, 2045 and 2055, respectively. Differences that are important for this study are listed in Table 1.

$\mathrm{T}$ a $\mathrm{b}$ l e 1 . Capacity factor and fuel loading with minor actinides

\begin{tabular}{l|c|c|c}
\hline \multicolumn{1}{c|}{ Parameter } & DEMO-FNS & PIHR & IHR \\
\hline $\begin{array}{l}\text { Capacity factor } \\
\text { Fuel loading }(\mathrm{MA}+\mathrm{Zr}), \mathrm{t}\left(\mathrm{H}_{2} \mathrm{O} \text { as }\right. \\
\text { coolant) }\end{array}$ & 0.3 & 0.8 & 0.95 \\
\end{tabular}

DEMO-FNS's 3D-geometric model is shown in Fig. 1. Fig. 2 gives a cut of a 3D-geometric model for Monte-Carlo calculations of neutron transport. The blanket contains 18 MA-bearing fuel assemblies (the transmutation area), with lithium salt filling the remaining space (the tritium breeding area).

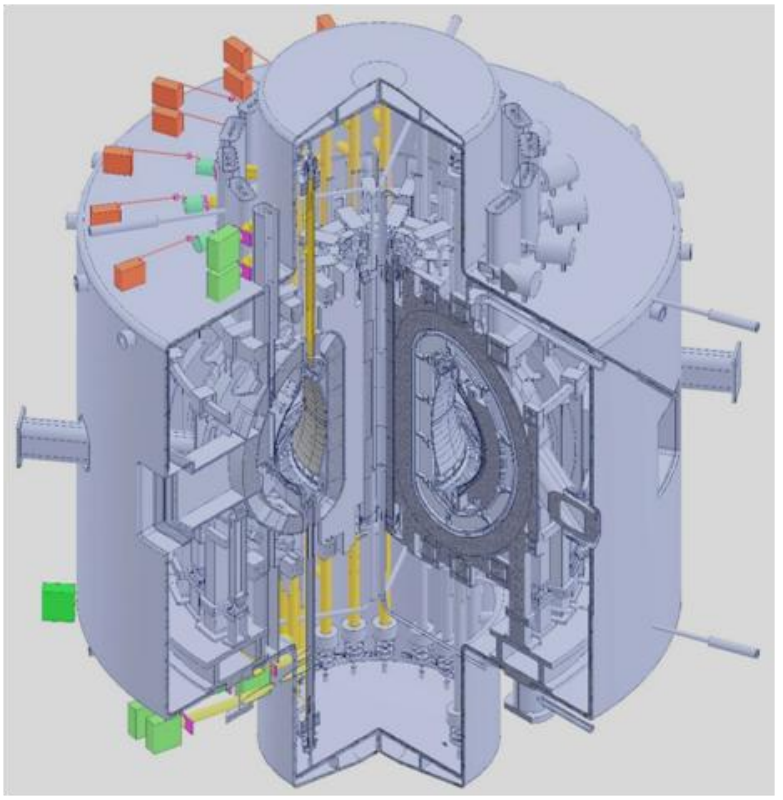

Fig. 1. 3D DEMO-FNS

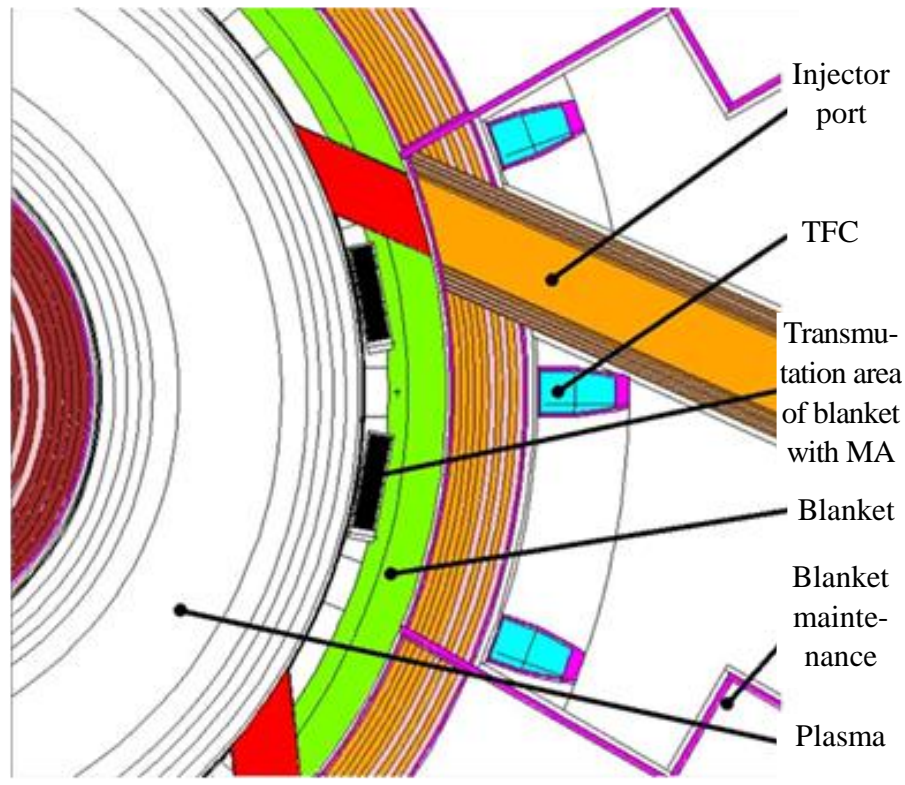

Fig. 2. Horizontal equatorial cut of DEMO-FNS model - transmutation area; TFC - Toroidal field coil 
Two coolants for the transmutation area, $\mathrm{CO}_{2}$ and $\mathrm{H}_{2} \mathrm{O}$, are considered. Whatever the coolant, it flows vertically, along the fuel rods and inside the assemblies' casings. $\mathrm{H}_{2} \mathrm{O}$ is chosen as a basic coolant option for the blanket. Average coolant density inside the assemblies is $0.37 \mathrm{~g} / \mathrm{cm}^{3}$ for $\mathrm{H}_{2} \mathrm{O}$, and should be $0.14 \mathrm{~g} / \mathrm{cm}^{3}$, if $\mathrm{CO}_{2}$ is employed. The use of $\mathrm{CO}_{2}$ instead of $\mathrm{H}_{2} \mathrm{O}$ encourages the $k_{\text {eff }}$ to grow (up to 1.04). In that case, it is necessary to decrease the total fuel loading (to $19.7 \mathrm{t}$ for DEMO-FNS).

A MA-Zr metal alloy was chosen as a fuel. This alloy has a theoretical density of $15 \mathrm{~g} / \mathrm{cm}^{3}$. Many researchers have considered this type of fuel $[8,11,12]$, and it has even been utilized in a fast reactor [13]. Fuel inventory details are shown in Table 2.

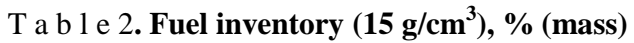

\begin{tabular}{c|c|c|c}
\hline Nuclide & Fraction, $\%$ & Nuclide & Fraction, \% \\
\hline${ }^{237} \mathrm{~Np}$ & 28.67 & ${ }^{90} \mathrm{Zr}$ & 2.05 \\
${ }^{241} \mathrm{Am}$ & 62.10 & ${ }^{91} \mathrm{Zr}$ & 0.45 \\
${ }^{242 m} \mathrm{Am}$ & 0.06 & ${ }^{92} \mathrm{Zr}$ & 0.70 \\
${ }^{243} \mathrm{Am}$ & 4.63 & ${ }^{94} \mathrm{Zr}$ & 0.72 \\
${ }^{244} \mathrm{Cm}$ & 0.49 & $9{ }^{96} \mathrm{Zr}$ & 0.12 \\
$\mathrm{MA}$ & 95.96 & $\mathrm{Zr}$ & 4.04 \\
\hline
\end{tabular}

The FISPACT-II inventory code [17] was used to quantify nuclide kinetics using a constant neutron spectrum. The neutron spectrum for the transmutation area was obtained using Monte-Carlo calculations of neutron transport. The spectrum was volume-averaged for the whole transmutation area. The use of a constant neutron spectrum in the nuclide kinetics calculations skewed the results, because of the interplay between fuel inventory evolution and the spectrum. However, in the case of a subcritical system with an external neutron source, this error should not be significant. Some contradictions in the assessment of this error are addressed in different publications $[9,10]$.

The ENDF/B-VI neutron data file was used for neutron transport calculations. Data needed to quantify nuclide kinetics came from the TENDL_2014 nuclear data library (CCFE-709 group structure).

\section{RESULTS AND DISCUSSION}

Neutron transport and nuclide kinetics analysis. Other important parameters for the transmutation area were calculated via neutron transport modeling:

— with $\mathrm{H}_{2} \mathrm{O}$ used as a coolant, volume-averaged total neutron flux $\bar{\Phi}_{n}=2.88 \cdot 10^{14}\left(\mathrm{~cm}^{2} \cdot \mathrm{s}\right)^{-1}$, average neutron energy $\bar{E}_{n}=3.52 \mathrm{MeV}$, and $k_{\mathrm{eff}}=0.95$;

— in the case of $\mathrm{CO}_{2}, \bar{\Phi}_{n}=3.02 \cdot 10^{14}\left(\mathrm{~cm}^{2} \cdot \mathrm{s}\right)^{-1}, \bar{E}_{n}=3.47 \mathrm{MeV}$, and $k_{\text {eff }}=0.91$.

From the obtained spectra it is deducted that $99 \%$ of neutrons have energies higher than $0.001 \mathrm{MeV}$, and $40 \%$ have energies higher than $1 \mathrm{MeV}$. In addition, when $\mathrm{CO}_{2}$ is used as a coolant, the spectrum is harder and reflects greater quantities of fission and, to a lesser extent, fusion neurons, than in the water-cooling case.

The obtained spectra were used to calculate average cross-sections. As shown in Fig. 3, there are three important actinides $\left({ }^{237} \mathrm{~Np},{ }^{241} \mathrm{Am},{ }^{243} \mathrm{Am}\right)$, whose capture-to-fission ratio, $\alpha$, is higher than 1 , despite a very hard neutron spectra inside the transmutation area $\left(\bar{E}_{n}>3 \mathrm{MeV}\right)$. At the same time, it must be emphasized that this ratio is only slightly higher than 1 , as opposed to $\alpha$ for light-water and fast reactors. As follows from Fig. 3, $\mathrm{CO}_{2}$ is the best cooling option for the transmutation of MAs, as it allows all predominant actinides to have the lowest $\alpha$ value. There is, however, one problem with this coolant, to be discussed below.

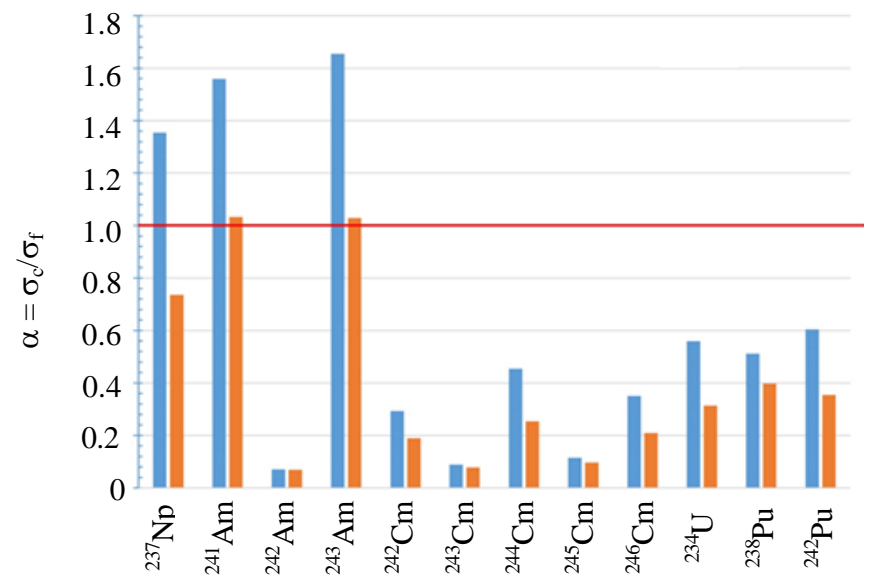

Fig. 3. Average capture-to-fission ratio, $\alpha$, obtained with different coolants: $=-\mathrm{H}_{2} \mathrm{O} ;=-\mathrm{CO}_{2}$ 
Key transmutation characteristics observed in each of the reactors are listed in Table 3. Among other things, the table provides data on how the mass of the most important actinides changes during irradiation.

$\mathrm{T}$ a b l e 3. Key MA transmutation characteristics observed in the FFHSs

\begin{tabular}{|c|c|c|c|c|}
\hline Parametr & DEMO-FNS $\left(\mathrm{H}_{2} \mathrm{O}\right)$ & DEMO-FNS $\left(\mathrm{CO}_{2}\right)$ & PIHR & IHR \\
\hline Total fuel loading, $\mathrm{t}$ & 26.24 & 19.7 & 26.24 & 41.68 \\
\hline Irradiation + Idle, $\mathrm{y}$ & 16.7 & 16.7 & 6.25 & 5.25 \\
\hline & & $\mathrm{Np}$ & & \\
\hline \multirow{7}{*}{$\begin{array}{l}\text { Change in actinide mass: accumulation }(+) \text {; } \\
\text { reduction }(-), \mathrm{kg} / \mathrm{t} \text { (per t of fuel) }\end{array}$} & $-9.9(3.5 \%)$ & $-5.2(1.8 \%)$ & $-19.1(6.7 \%)$ & $-100.3(35.0 \%)$ \\
\hline & $-70.2(10.5 \%)$ & $-63.2(9.5 \%)$ & $-60.8(9.1 \%)$ & $-241.8(36.2 \%)$ \\
\hline & & $\mathrm{Cn}$ & & \\
\hline & $-0.4(7.7 \%)$ & $-1.0(21.2 \%)$ & $+2.8(57.5 \%)$ & $+17.7(358.1 \%)$ \\
\hline & +2.4 & +1.6 & +0.9 & +3.0 \\
\hline & & $\mathrm{Pu}$ & & \\
\hline & +43.5 & +29.5 & +41.7 & +174.0 \\
\hline Burnup of actinides, $\%$ (mass) & 3.6 & 4.0 & 3.6 & 15.4 \\
\hline Total actinide incineration, $\mathrm{kg}$ & 906.4 & 755.0 & 904.4 & 6148.0 \\
\hline Efficiency of actinide incineration, $\mathrm{kg} / \mathrm{year}$ & 54.3 & 45.2 & 144.7 & 1171.0 \\
\hline Time-averaged fission power, (thous. MW) & 472 & 398 & 472 & 3100 \\
\hline
\end{tabular}

A more detailed analysis of the final fuel inventory shows that the largest $\mathrm{Pu}$ fraction is comprised of ${ }^{238} \mathrm{Pu}$ $(80 \%),{ }^{242} \mathrm{Pu}(11 \%)$ and ${ }^{240} \mathrm{Pu}(6.5 \%) .{ }^{234} \mathrm{U}$ represents $\mathrm{U}$ almost entirely (99\%). Although the total mass of $\mathrm{Cm}$ decreases, new isotopes ${ }^{242} \mathrm{Cm}(12 \%)$ and ${ }^{245} \mathrm{Cm}(2 \%)$ are produced due to neutron capture on Am and initial ${ }^{244} \mathrm{Cm} .{ }^{237} \mathrm{~Np}(37 \%)$ and ${ }^{241} \mathrm{Am}(60 \%)$ subjected to neutron capture generate a chain leading to ${ }^{238} \mathrm{Pu}$. ${ }^{234} \mathrm{U}$ occurs as a product of ${ }^{238} \mathrm{Pu} \alpha$-decay.

As mentioned above, a simple change of the transmutation area coolant to $\mathrm{CO}_{2}$ causes $k_{\text {eff }}$ to grow to 1.04 and requires the total fuel loading to be decreased to $19.7 \mathrm{t}$. With $\mathrm{CO}_{2}$, the qualitative change in actinides' combined mass is the same as with $\mathrm{H}_{2} \mathrm{O}$, but quantitative parameters are different. The burnup of actinides increases by $14.3 \%$, however the total actinide incineration is less because of a lower fuel loading. The amount of transmuted $\mathrm{Np}$ and $\mathrm{Am}$ is smaller, as is the accumulation of $\mathrm{U}$ and $\mathrm{Pu}$, while the amount of transmuted $\mathrm{Cm}$ is twice as large. This change is due to a greater hardness of the $\mathrm{CO}_{2}$-associated spectrum, resulting in a neutron capture cross-section decrease that overrides the increase in the fission cross-sections. The result is the overall crosssection decrease, and the reduction of the transmutation rate. At the same time, due to the lower neutron capture rate, $\mathrm{Cm}$ is less than before, while its fission rate is very high (owing to its isotopes' low $\alpha$ ). Consequently, the transmuted amount of $\mathrm{Cm}$ is larger than before.

Initially, fuel contains a small amount of $\mathrm{Cm}$. For this reason, while its isotopes undergo fission at a high rate, new $\mathrm{Cm}$ isotopes emerge due to the neutron capture reaction on other actinides. The $\mathrm{Cm}$ amount may even increase (as reported in [15]): the neutron capture rate for other actinides is higher than the fission rate of $\mathrm{Cm}$. This situation is typical for the operation of both the pilot industrial (PIHR) and industrial (IHR) reactors.

The ultimate purpose of the FFHS project is to create an industrial-scale hybrid reactor. The IHR will feature the same build as the DEMO-FNS and PIHR and similarly produce $40 \mathrm{MW}$ of fusion power, but will have a larger fuel loading (40 t). This implies a more intense neutron flux in the transmutation area. For this study, it is assumed that the neutron flux will increase five times compared to the demo reactor using $\mathrm{H}_{2} \mathrm{O}$ as a coolant. The high capacity factor (0.95) and large fuel loading should make for a good performance. Not only for MA transmutation, but also for electrical power production exceeding the reactor's operational consumption, so this facility will solve the problem of MA transmutation not only from a technical, but also from an economical, perspective.

For the IHR, fuel inventory evolution during the operating cycle is similar to that for the PIHR with the exception that the transmutation rate is higher due to a higher neutron flux. The IHR will be able to produce more than $3 \mathrm{GW}$ (th) and $\sim 1 \mathrm{GW}$ (el), while its own electrical energy consumption will be about $200 \mathrm{MW}$.

FFHS integration in Russia's two-component nuclear power system and the potential for MA reduction. In the first part of this study, the potential of FFHSs for the MA transmutation was defined. However, what also matters is the impact of FFHSs' operation on the nuclear power system that reduces the total amount of MA. For this purpose, the Universal System Model designed by E.V. Muraviev [16] was used. 
Fig. 4 shows the historic and prospective evolution of Russia's nuclear power net installed capacity. In 2100 , the last thermal reactor will be decommissioned and only fast reactors will remain.

Nuclear power net installed capacity determines the production of SNF (and related MAs), as well as the total amount of MAs accumulated over a given year.

Fig. 5 shows the total amount of MAs in the system during successive five-year periods between 1970 and 2130. $287 \mathrm{t}$ of MAs accumulate in SNF, if there is no fuel reprocessing, as shown with the blue curve. The orange curve is for actinides, whose inventory is scaled down with the help of hybrid reactors. The grey curve represents MAs managed through hybrid reactors' operation and initial fuel loadings in the blankets, so it is possible to reduce the total amount by $28 \%$ ( $82 \mathrm{t}$ ) or $43 \%$ (122 t), taking into account the initial fuel loadings.

The rate of MA production in the system was determined obtained based on information about MA accumulation during the assumed period of time. As follows from obtained data, it will be necessary to incinerate more than $4 \mathrm{t} / \mathrm{year}$ of MAs at the end of this timeline. This means that at least 4 facilities with IHR parameters will be needed. In the interim, two more IHRs can be put

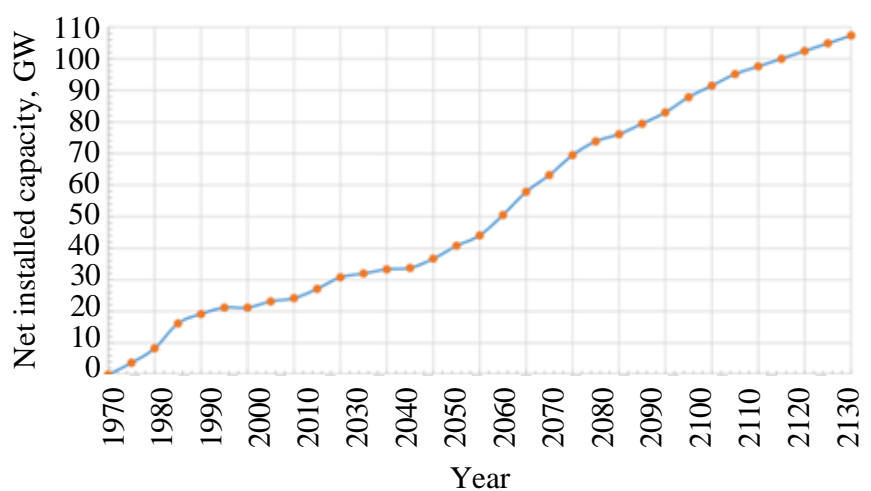

Fig. 4. Evolution of Russia's nuclear power the net installed capacity

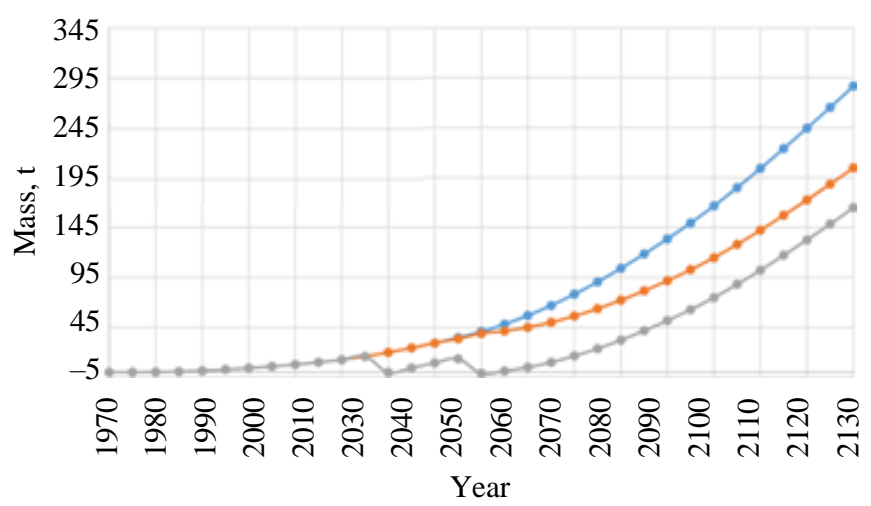

Fig. 5. Russian nuclear power system's total MA inventory: $\bullet-$ without PT; • — reduced amount by FFHR-operation; • — reduced amount by FFHR-operation and initial load into service, in 2090 and 2120. In that case, the MA amount could be reduced by $48 \%$ (142 t) or 88\% (262 t) taking into account the initial fuel loadings.

\section{CONCLUSION}

This research was performed as part of the Kurchatov Institute's project on the development of fusionfission hybrid reactors in Russia. This study shows that the application of fusion-fission hybrid reactors possesses a promising application potential for the transmutation of minor actinides. Calculations on neutron transport and nuclide kinetics were performed for three reactor types intended for different purposes (demonstration, pilot-industrial, and industrial). The capture-to-fission ratio was found to be is less than 1 for most actinides, which should favor an effective MA transmutation. The exceptions are ${ }^{237} \mathrm{~Np}$ (only if $\mathrm{H}_{2} \mathrm{O}$ is used as a coolant), ${ }^{241} \mathrm{Am}$ and ${ }^{243} \mathrm{Am}$, with $\alpha$ slightly higher than 1 . The use of $\mathrm{CO}_{2}$ as a coolant required the reduction of the total fuel load, thus the potential advantages of this coolant for transmutation are neutralized. This can be improved via optimization of the transmutation area for this coolant. During irradiation, new actinides emerge. This is important in light of the fuel potential multicycle reprocessing and reuse. Determining an equilibrium inventory for the FFHS's fuel is an objective for future research, as is the analysis of the inventory evolution and its influence on the neutron spectrum during irradiation and vice versa.

For effective MA transmutation, in terms of not only technical but also economical parameters, it is necessary to use a FFHS with a large fuel loading and high capacity factor, such as the IHR, which is able to incinerate more than $1 \mathrm{t}$ of actinides per year and generate about $1 \mathrm{GW}$ of electrical power.

A system analysis of nuclear power in Russia, performed with the involvement of the hybrid reactors, highlight the problems associated with the absence of MA transmutation and the potential of FFHSs to reduce these hazards.

As can be seen from the reported results, there is a deficit of extracted MA, even for optimized development scenarios. At the same time, it is necessary to decommission the DEMO-FNS and PIHR (at least as burner reactors), and to abandon one additional IHR, which is needed due to the rate of MA accumulation in the system. It is also necessary to delay the commissioning of 2 other additional IHRs. 
For the scenarios considered in the study, the deficit problem of extracted MA may be overcome by around 2075. However, in the case of additional IHRs, the MA deficit takes place again at the time when the second and the third IHR is commissioned. This can be improved by using imported SNF, which can be considered a service of radioactive waste management. The results obtained also highlight the need to speed up the commissioning of SNF reprocessing plants to ensure the required amount of MAs for FFHS fuel manufacturing.

It follows from the analysis performed that, over the period of time considered, it is possible to decrease by 2130 the amount of MA in the system by $\sim 28 \%$, in the case of just 1 IHR, and by $\sim 48 \%$, in the case of two additional IHRs. If MAs loaded in the FFHS blankets are not treated as waste, then the amount of MAs isolated from the system may be up $\sim 43 \%$ or, if two additional IHRs are there, up $\sim 88 \%$.

\section{REFERENCES}

1. Salvatores M., Palmiotti G. Radioactive waste partitioning and transmutation within advanced fuel cycles: achievements and challenges. — Prog. Part. Nucl. Phys., 2011, vol. 66, p. 144-166; doi:10.1016/j.ppnp.2010.10.001.

2. Adlys G. Sources of radiotoxicity in spent nuclear fuel. — In: Proc. of the Intern. Symposium on Biomedical Engineering and Medical Physics. Riga, Latvia, 10_12 October 2012; Dekhtyar Y., Katashev A., Lancere L. Eds. — Berlin: Springer, 2013, vol. 38, p. 213-216, ISBN 978-3-642-34196-0.

3. Stacey W. Transmutation missions for fusion neutron sources. — Fusion Eng. Des., 2007, vol. 82, p. 11-20; doi: 10.1016/j.fusengdes.2005.12.005.

4. Adamov E.O., Vlaskin G.N., Lopatkin A.V., Rachkov V.I., Khomyakov Y.S. Radiation equivalent treatment of radioactive nuclides in nuclear fuel cycle - effective alternative to the delayed solution of spent nuclear fuel accumulation problem. - News of the Russian Academy of Sciences, Energy, 2015, vol. 6, p. 15-25.

5. Crossland I. Nuclear Fuel Cycle Science and Engineering; Woodhead Publishing Limited. Cambridge, UK, 2012; ISBN 978-085709-073-7.

6. Stacey W.M. Solving the spent nuclear fuel problem by fissioning transuranics in subcritical advanced burner reactors driven by tokamak fusion neutron sources. — Nucl. Technol., 2017, vol. 200, p. 15—26; doi: 10.1080/00295450.2017.1345585.

7. Wu Y., Jiang J., Wang M., Jin M., Team F. A fusion-driven subcritical system concept based on viable technologies. - Nucl. Fusion, 2011, vol. 51, p. 103036; doi: 10.1088/0029-5515/51/10/103036.

8. Yang C., Cao L., Wu H., Zheng Y., Zu, T. Neutronics analysis of minor actinides transmutation in a fusion-driven subcritical system. - Fusion Eng. Des., 2013, vol. 88, p. 2777—2784; doi: 10.1016/j.fusengdes.2013.04.021.

9. Ridikas D., Plukiene R., Plukis A., Cheng, E. Fusion-fission hybrid system for nuclear waste transmutation (I): characterization of the system and burn-up calculations. - Prog. Nucl. Energy, 2006, vol. 48, p. 235-246; doi: 10.1016/j.pnucene.2005.09.004.

10. Furudate Y., Shishido H., Yusa N., Hashizume H. Construction of minor actinides reduction scenario in Japan utilizing fusion reactors. - Prog. Nucl. Energy, 2018, vol. 103, p. 28 -32; doi: 10.1016/j.pnucene.2017.11.003

11. Hong S.H., Kim M.H. Neutronic investigation of waste transmutation option without partitioning and transmutation in a fusionfission hybrid system. — Nucl. Eng. Technol., 2018, vol. 50, p. 1060—1067; doi: 10.1016/j.net.2018.06.008.

12. Stacey W.M., Van Rooijen W., Bates T., Colvin E., Dion J., Feener J., Gayton E., Gibbs D., Grennor C., Head J. et al. A TRU$\mathrm{Zr}$ metal-fuel sodium-cooled fast subcritical advanced burner reactor. - Nucl. Technol., 2008, vol. 162, p. 53-79; doi: $10.13182 / \mathrm{nt} 08-\mathrm{a} 3933$.

13. Capriotti L., Brémier S., Inagaki K., Pöml P., Papaioannou D., Ohta H., Ogata T., Rondinella V. Characterization of metallic fuel for minor actinides transmutation in fast reactor. - Prog. Nucl. Energy, 2017, vol. 94, p. 194-201; doi: 10.1016/j.pnucene.2016.04.004.

14. Sublet J.-C., Eastwood J., Morgan J., Gilbert M., Fleming M., Arter W. FISPACT-II: an advanced simulation system for activation, transmutation and material modelling. — Nucl. Data Sheets, 2017, vol. 139, p. 77—137; doi: 10.1016/j.nds.2017.01.002.

15. Wang M., Zeng Q., Jiang J., Wu Y. Neutronics analysis and optimization for fusion driven subcritical spent fuel burning system. - J. Fusion Energy, 2015, vol. 34, p. 598 -603; doi: 10.1007/s10894-015-9846-2.

16. Muraviev E.V. USM-1 System Model Generator. Preprint by FSUE RDIPE (NIKIET) № ET-08/75. Moscow, Russia, 2008.

\section{AUTHORS}

Mikhail Shlenskii, assistant-researcher, National Research Nuclear University Moscow Engineering Physics Institute, Plasma Physics Department, Kashirskoe Hwy 31, 115409 Moscow, Russia, shlenskiy_mn@nrcki.ru

Boris V. Kuteev, Professor, Deputy Head Tokamak Department Fusion Research Centre; NRC «Kurchatov Institute», 1, Academika Kurchatova sq., Moscow, 123182, Russia, Kuteev_BV@ nrcki.ru

Received 15 January 2021

Revised 16 March 2021

Accepted 25 March 2021

Problems of Atomic Science and Technology Ser. Thermonuclear Fusion, 2021, vol. 44, issue 2, pp. 139—144 